\title{
The Assessment of the Green Transformation Capacity in Low Carbon Economy of China
}

\author{
Chongmei Wang ${ }^{1,2, *}$ \\ ${ }^{1}$ School of Administration, Shandong Institute of Business and Technology, Yantai 264005, China; ${ }^{2}$ Nicholas School of \\ Environment, Duke University, Durham, 27708, NC, America
}

\begin{abstract}
This paper looks at system innovation as a complex system. It dynamically evaluates the regional green transformation capacity through data envelopment analysis (DEA). It analyzes, in terms of resource allocation efficiency, the interaction between the internal and external mechanisms of the innovation system and of the green transformation system. A case study of the green transformation of the Jiaodong Peninsula (Qingdao, Yantai and Weihai) concludes that there was good coordination between the innovation and the green transformation systems during years 2006 and 2009, but there was lack of coordination in years 2005 and 2010. The main reason for limited coordination is the lack of elements of innovation capability. System innovation capacity cannot be fully translated into green transformation capacity, and this lag weakens the supporting role of other developments in the field of innovation for the transition. The paper concludes with a discussion on the value of research applications and recommendations for future research direction.
\end{abstract}

Keywords: Green transformation, green transformation capacity, innovation capacity, system innovation.

\section{INTRODUCTION}

John Rensenbrink was in the typical book, "against all odds: green transformation of American politics". He advocated green transformation and in the transformation method based on the theoretical aspects of innovation [1]. Geels proposed multi-level transformation method and explain motivation mechanism in 2001; Rotmans proposed to guide the evolution of management methods by replacing a control command----control mode in 2000 [2].

Our country needs to promote green transformation in order to deal with international pressure to address climate change and cope with growing constraints on environmental resources. Faced with the research of the green transformation, domestic research has just started focusing both in the theory and practice. At present, academic research mostly concentrates on industrial transformation, but there is no literature on the transformation in the public sectors [3]. The research on the meaning and methods of green transformation, including the factors that influence it, is still in at an early stage. The understanding of "green transformation" theory is very limited, though some cities have begun exploratory work on the green transformation and have made some progress; however, because of the short time and single subject, the theory of green transformation has not yet been developed. Although the study does not directly address the regional economic restructuring, but the results of their research on regional economic transformation has important references.
According to the British scholar's view, the green idea produced in 1972, Dennis Meadows led the 17-member group, presented a paper entitled "Limits to Growth" report to the Club of Rome, which was also the published first green research report in the Club of Rome. In the report, he pointed out that the supply of energy could not be infinitely stone carbon, and therefore economic growth was limited. In the report, both boldly predicted the advent of a global catastrophe, and the design of the "zero growth" plan, caused uproar in the world [4].

After that, Jigme Singye of King of Bhutan - Singh proposed that "Gross National Happiness" (GNH) concept. Considering basic questions of life was how to maintain a balance between material life and spiritual life, and to advocate the development of national policies to increase the spiritual life, peace of mind and happiness national considerations [5].

1973-2007, the EU implemented a total of six "Environmental Action Plan", in which the first six Environmental Action Plan (The Sixth Environment Action Programmer of the European Community 2002-2012) proposed the "Environment 2010: Our Future, our choice". It is concerned about climate change, protection of the relationship between natural resources and biodiversity, the environment and health problems among the sustainable use of natural resources and waste management, requiring the whole society must strive to achieve the decoupling economic growth from environmental degradation.

Since 2003, National Bureau of Statistics conducted a physical accounting of natural resources; in 2004, the National Bureau of Statistics and the State Environmental Protection Administration established a joint task group of green 
GDP, green GDP accounting research and exploration. On the basis of China's economic and resource consumption accounting that China had been taking a black or brown economic growth model, advocated green development in the future [6]. The entire history of human civilization and economic development was divided into yellow, black and green civilization three stage. Yu Hai promoted and achieved green development needs to start from the root causes of the problem, systematic innovation, systems thinking to promote green development of the basic strategies and approaches [7]. CASS Institute of Industrial Economy Task Force (2011) raised the need to accelerate the transformation of China's industrial green innovation mechanism. Li Xiaoxi noted that the green economy was for economic development, adding new constraints on consumers, businesses and government decision-making [8].

Since 1990, many academic researchers have studied on resource-exhausted cities in-depth exploration, choosing Taiyuan, Fushun, Fuxin, Daqing as the main object of study, at the same time, many scholars have published a number of papers to explore the area from a different angle Transition issues and regional transformation mode to think and countermeasures. On the resource-based city of Taiyuan, she proposed green transition costs, timing, and the establishment of urban green transformation of complex systems. Urban green development capability was evaluated.

By studying the theory and practice of green transformation, we believe green transformation system is a complex giant system. In order to protect the environment, save energy, improve the quality of economic growth and achieve the goal of sustainable development; we need to transmit from black or brown economy to a green economy.

This study points out that the regional green transformation ability refers to the transformation of the innovations systems and coordination ability. This study uses the analytic hierarchy process (AHP) and data envelope analysis (DEA) methods to analyze the complex system of regional coordination model and the green transformation system. The paper concludes with suggestions for future research.

\section{RESEARCH METHOD AND MODEL CONSTRUC- TION}

Data envelopment analysis (DEA) is a multi-pectoral indicators of the same type of inputs and outputs multi-index (also called the decision making unit decision making unit DMU) conducted a comprehensive evaluation of the relative effectiveness of the method, as well as research put in more and more powerful tool output production function. Generally used to measure performance using the input and output of a unit than the index, especially when all the input and output indicators can be converted into one unit, to give the decision-making units to be assessed the performance of the sort, then the input-output ratio is a good indicators. But in the case of multiple-input multiple-output is often impossible, in 1978, Charles Burns (A. Charnes), Cooper (W.W. Cooper) and Rhodes (E. Rhodes) jointly published three "Effectiveness measure" academic decision making units (Measuring the efficiency of decision making units) proposed the first DEA model, evaluate the relative effectiveness of departments, for the same type of decision-making has multiple inputs and multiple outputs Performance assessment unit provides tools and methods, this model is called C2R model [9].

Regional Green Transformation system as a complex giant system, to achieve green transformation, participating companies and government involvement are not enough, you also need public participation, that is, the need to protect systems, policies, and in business, public long-term efforts under the system of innovative practices make the transformation, we can see the green transformation system is an innovative system [10].

British scholar Cook (1996) and Morgan (Morgan) coauthored "learn through Network: Regional Innovation and Baden - Wuerttemberg lessons" in the report, the two scholars gave the meaning of regional innovation systems, is a division of labor in the space of mutual collaboration and joint production of the manufacturing sector, schools and research institutes constitute concerted efforts, advocacy and generate innovative regional organizational structures, The core structure is proposed regional innovation linkages between the two types of the body, one subject is the region's manufacturing industry cluster, also including services such as circulation and so on; the other is to support the industry body, such as universities, research institutes, training institutions, industry associations [11].

Since 2000 year, domestic many scholars have launched studies of regional innovation systems, and put forward their point of views, for example, Luo Shougui, Huang Lucheng, Liu Shuguang, Tianli Qin, Gu Xin, they thought the regional innovation system was composed of interrelated, innovation network system including the main elements and non-subject factors. In the regional innovation system, its goal is to promote innovation, regional economic development, geographic organizational structure of the system, to optimize the industrial structure and the establishment of regional competitive advantage [12].

The paper looks as green transformation system in the impact of the population, economic resources, and environmental external factors, from business, industry, government and the public as the main through the implementation of technical, institutional, policy, management and service system innovations driven by internal forces transformation process, therefore, green transformation system is an innovative multi-dimensional, the effective integration of crosscutting issues. The paper is based on the synergy relationship between system innovation and green transformation and evaluated on regional green transformation capacity. First of all, why is the green transformation? in order to solve the economic, resource and environmental conflicts, and the urgent need for the transformation of economic development mode, and its development from a single environmental goals to sustainable development, therefore, to achieve the transformation of the system must be innovative business, industry and government-based, and require participation awareness. Secondly, where to turn green transformation? Economic restructuring, green transformation concepts elaborated, and the Shandong Peninsula in transition situations to System Overview, thus building the Shandong Peninsula Blue Economic Zone area for green transformation connotation background, scientific definition of the theoreti- 
cal basis. And in China in 2030 to achieve green development as the goal, according to achieve green development standards of Western countries to give direction of the transformation model. Finally, how to achieve the transition? Establishing the collaborative model of the regional green transformation. Choosing Qingdao, Yantai and Weihai as the example of empirical research, through empirical analysis to identify issues, and affecting the region's green transformation capabilities, ability level or regional green transformation reason. It Proposed the strategy from the perspective of regional innovation systems green transformation and implemented countermeasures to other areas with similar conditions in Chinese.

The key problems of transformation effect use the data envelopment analysis (DEA) method for processing the data. First, the DEA method is applied to solve multiple inputs and multiple outputs as a synthetic evaluation While there are many other methods, mostly confined to output, in the treatment of multiple inputs multiple outputs, the DEA method is most effective. Second, the input and output data can be calculated by different units for the index and do not need a certain relationship with the index which would give the index subjective weight. Again, the DEA method does not need knowing the production function form of its parameters in advance. Of course there are some defects of the DEA analysis method; for example, the decision making unit (DMU) is always set from a view of the most advantageous for themselves, leading to weigh the different with the difference of the DMU so that it makes the characteristic of each DMU lack of comparability [13]. In view of this, this article studied on evaluation index of green transformation effect by AHP and DEA.

In 1978, A. Charnes, W. W. Cooper and E. Rhodes published academic paper on measuring the efficiency of DMU and the model was called as $\mathrm{C} 2 \mathrm{R}$ mode 1 [9]. As follows: with $n$ decision units $D(j=1,2, \ldots, n)$, each DMU has the same number of inputs $m$, and the same number of outputs $p$. respectively for different economic index said, Thus, Make up a $n$ evaluation unit of input and output index many index of evaluation system, with $\mathrm{Xij}$ said, as shown in Fig. (1) shows. The input and output matrix can be expressed as follows:

Input $12 \ldots \mathrm{N}$ evaluation unit

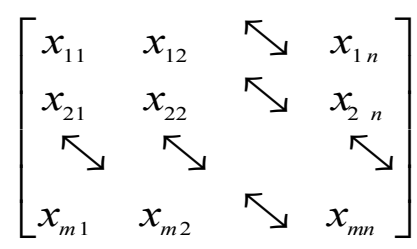

Output

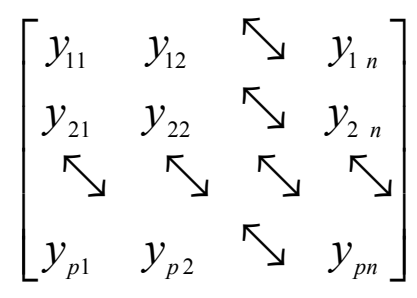

Fig. (1). DEA input-output system model.

\section{DYNAMIC EVALUATION OF REGIONAL GREEN TRANSFORMATION CAPACITY}

\subsection{Data Sources}

The data used in this analysis comes from the Shandong province statistical yearbook and Shandong province Environment Statistical Bulletin. The focus is on the cities of Qingdao, Yantai and Weihai which are representative of the green research transformation in the Jiaodong peninsula. To deal with missing or inconsistent data, we used the expert scoring and nonlinear programming methods, and a survey with the general public, consistently with this paper's view that the public is the main body of the green transformation. The survey was used each year in the period 2008-2012, to ask the opinions of college students, urban residents, company workers, and teachers. The SPSS software was used to process the data.

We applied AHP to evaluate system innovation capacity and green transformation capacity comprehensively, using the whole distance (poor) standardized method to standardize the original data and assess different impact dimensions. From these methods we obtained estimates of the green transformation capacity and system innovation ability evaluation index for the cities of Yantai, Qingdao, and Weihai.

\subsection{Data Analysis}

From Table $\mathbf{1}$ it is clear that in 2005, the $\theta$ values for Qingdao, Yantai, and Weihai are less than 1. This means the in the three cities of system innovation ability and green transformation effect both the DEA effective, already failed to achieve innovation investment to the transition of the output effective transformation. The three typical Jiaodong peninsula city of innovation and change the cause of the coordination from innovation investment perspective, Qingdao policy innovation, system innovation and management innovation ability appear redundancy Yantai management innovation and policy innovation ability appear redundancy; Weihai management innovation and service innovation ability appear redundancy. That is because the innovation ability hasn't been effectively transformated into transformation effect, which affected the transformation of the green of the ability.

In 2006-2009, Qingdao, Yantai and Weihai $\theta$ value are equal to 1 , achieves the weak DEA effectively, including relaxation variable s-and $s+$ are equal to 0 , it is to say that the three typical Jiaodong peninsula urban realized the innovation investment to the transition of the output effective transformation. This is because they are in the early $21^{\text {st }}$ century began to promote innovation practice of transformation, after a few years of development, innovation and transformation in the coordination of preliminary achievements have been made to bouts of coordination state.

In that 2006-2009, these three cities green transformation ability owned a certain degree of improvement.

In 2010, Qingdao and Yantai $\theta$ value was less than 1, it indicated that DEA was invalid. Analyzing the reason, the transformation from the output Angle analysis, Qingdao in population and the transformation of the environment results 
Table 1. @S-, S+ of DMU from 2005-2010 year in Qingdao, Yantai, Weihai.

\begin{tabular}{|c|c|c|c|c|c|c|c|c|c|}
\hline \multirow{2}{*}{$\begin{array}{c}\text { DMU } \\
\text { Serial } \\
\text { Number }\end{array}$} & \multicolumn{3}{|c|}{2005} & \multicolumn{3}{|c|}{2006} & \multicolumn{3}{|c|}{2007} \\
\hline & Qingdao & Yantai & Weihai & Qingdao & Yantai & Weihai & Qingdao & Yantai & Weihai \\
\hline$\Theta$ & 0.612 & 0.289 & 0 & 1 & 1 & 1 & 1 & 1 & 1 \\
\hline \multirow{5}{*}{$\mathrm{S}^{-}$} & 0 & 0 & 0 & 0 & 0 & 0 & 0 & 0 & 0 \\
\hline & 0.886 & 0.097 & 0.093 & 0 & 0 & 0 & 0 & 0 & 0 \\
\hline & 0.546 & 0 & 0 & 0 & 0 & 0 & 0 & 0 & 0 \\
\hline & 0.139 & 0.129 & 0.176 & 0 & 0 & 0 & 0 & 0 & 0 \\
\hline & 0 & 0 & 0 & 0 & 0 & 0 & 0 & 0 & 0 \\
\hline \multirow{8}{*}{$\mathrm{S}^{+}$} & 0 & 0 & 0 & 0 & 0 & 0 & 0 & 0 & 0 \\
\hline & 0 & 0 & 0 & 0 & 0 & 0 & 0 & 0 & 0 \\
\hline & 0 & 0 & 0 & 0 & 0 & 0 & 0 & 0 & 0 \\
\hline & 0 & 0 & 0 & 0 & 0 & 0 & 0 & 0 & 0 \\
\hline & 0 & 0 & 0 & 0 & 0 & 0 & 0 & 0 & 0 \\
\hline & 0 & 0 & 0 & 0 & 0 & 0 & 0 & 0 & 0 \\
\hline & 0 & 0 & 0 & 0 & 0 & 0 & 0 & 0 & 0 \\
\hline & 0 & 0 & 0 & 0 & 0 & 0 & 0 & 0 & 0 \\
\hline
\end{tabular}

\begin{tabular}{|c|c|c|c|c|c|c|c|c|c|}
\hline \multirow{2}{*}{$\begin{array}{c}\text { DMU } \\
\text { Serial } \\
\text { Number }\end{array}$} & \multicolumn{3}{|c|}{2008} & \multicolumn{3}{|c|}{2009} & \multicolumn{3}{|c|}{2010} \\
\hline & Qingdao & Yantai & Weihai & Qingdao & Yantai & Weihai & Qingdao & Yantai & Weihai \\
\hline$\Theta$ & 1 & 1 & 1 & 1 & 1 & 1 & 0 & 0 & 1 \\
\hline \multirow{5}{*}{$\mathrm{S}^{-}$} & 0 & 0 & 0 & 0 & 0 & 0 & 0 & 0 & 0 \\
\hline & 0 & 0 & 0 & 0 & 0 & 0 & 0 & 0 & 0 \\
\hline & 0 & 0 & 0 & 0 & 0 & 0 & 0 & 0 & 0 \\
\hline & 0 & 0 & 0 & 0 & 0 & 0 & 0 & 0 & 0 \\
\hline & 0 & 0 & 0 & 0 & 0 & 0 & 0 & 0 & 0 \\
\hline \multirow{8}{*}{$\mathrm{S}^{+}$} & 0 & 0 & 0 & 0 & 0 & 0 & 0 & 0 & 0 \\
\hline & 0 & 0 & 0 & 0 & 0 & 0 & 0 & 0.025 & 0.001 \\
\hline & 0 & 0 & 0 & 0 & 0 & 0 & 0 & 0 & 0 \\
\hline & 0 & 0 & 0 & 0 & 0 & 0 & 0 & 0 & 0 \\
\hline & 0 & 0 & 0 & 0 & 0 & 0 & 0.018 & 0 & 0 \\
\hline & 0 & 0 & 0 & 0 & 0 & 0 & 0 & 0 & 0.003 \\
\hline & 0 & 0 & 0 & 0 & 0 & 0 & 0 & 0.012 & 0.014 \\
\hline & 0 & 0 & 0 & 0 & 0 & 0 & 0.461 & 0.027 & 0 \\
\hline
\end{tabular}

in redundancy, failed to realize effective conversion; So, because of the slow process of transformation, continue to building the innovative city, the innovation ability of Qingdao and Yantai is rising, leading to their transformation effect can't into system innovation of the driving force. Weihai $\theta$ value is equal to 1 , which is the weak DEA effective, but failed to meet DEA effective state. In the view of transformation output, weihai in the enterprise, the transformation of economic and environmental field results in redundancy, can't effectively into the innovation ability, thus weakening the other areas of innovative support role transformation. But what different it does from 2005 is that the reason disorder in 2010 and 2005 is opposite, Qingdao, Yantai, Weihai and in
2010 and 2005 new disorder is exactly the opposite, because a few years before innovation ability constantly enhance the accumulation, and Qingdao and Yantai has basic formed a reasonable economic structure and development mechanism, so transformation process was slowed down, and its innovation ability is in a state of rapid ascension, rich innovation ability in short term can't into green transformation of the power, which caused both on the static can not be harmonious, so we can see, Qingdao and Yantai are in a higher level of floating coordinate. The population system and resource system transformation effects are weak in Weihai, so it makes the whole process of green transformation lags behind others, which in a general coordination situation. 
Use the same method, put the transformation effect as the input index, and the system innovation ability as output index, so that we conclude that 2005-2010 $\theta$, s-s + data similar. Therefore, this paper will be no longer etc.

\section{CONCLUSION}

Through the qualitative analysis and quantitative evaluation we can get the following conclusions: (1) the case analysis evaluation can find based on system innovation of Jiaodong peninsula green transformation of the existence of the not harmonious factors, found the system innovation and transformation in the development of the interaction between green not coordination mechanism, to find cause the system innovation and green transformation of the key factors in the coordination, green transformation strategy for the policy direction and provide practical basis (2) regional green transformation is complex giant regional innovation system. System innovation ability and green transformation ability is the positive correlation, and improve the system of innovation ability can promote the development of regional green transformation ability, but different dimensions of the system innovation ability can bring different function to the green transformation ability. (3) in the main body of the transformation ,government and enterprise play a key role, and by establishing a closed loop type circular economic development mode and opening innovation network system, especially to strengthen management innovation, innovation of policy and system innovation, for improving the green transformation capacity to provide mechanism safeguard and system.

\section{CONFLICT OF INTEREST}

The author confirms that this article content has no conflict of interest.

\section{ACKNOWLEDGEMENTS}

Shandong Collaborative Innovation Center of Energy Economy (2014 SDXT011).

\section{REFERENCES}

[1] R. John, Against All Odds: The Green Transformation of American Politics. Raymond, ME: Leopold, 1999.

[2] J. Rotmans, "Transformation Management for Sustainable Development," Mastrieht, International Centre for Integrative Studies, 2000.

[3] C. Zhang, "In China Study on Resource City Green Transformation Complex System-Shanxi Province Taiyuan City," Tianjing, Nankai, pp. 26-27, 2010.

[4] D.H. Meadows, J. Randers, and W.W. Behrens, "The Limits to Growth London," Earth Island, 1972.

[5] J. Xia, and B. From, "Gross National Happiness' Look as environmental protection and economic development of our country," Study on Mao Zedong and Deng Xiaoping Theory, no. 5, pp. 65-68. 2007.

[6] A. Hu, "China: green development and green GDP(1970-2001 year)," China Science Fund, vol. 02, pp. 84-89, 2005.

[7] H. Yu, "China's "1025" green development roadmap," Environmental Protection, vol. 01, pp. 12-13, 2011.

[8] X. Li, and B. Hu, "Economy New Transition in China," Encyclopedia of China Publishing House, 2011, pp. 350-353.

[9] W. W. Cooper, L.M. Seiford, and K. Tone, "Envelopment Analysis,” Boston, Klumer, 1999, pp. 425-432.

[10] C. Philip, "Regional innovation systems: institutional and organizational dimensions," Research Policy, vol. 26, pp. 477-489, 1997.

[11] B. T. Asheim, and A. Isakson, "Location, agglomeration and innovation: towards regional innovation systems in norway," European Planning Studies, vol. 3, pp. 298-325, 1997.

[12] D. J. Zhu, "Based on the PS R of Chinese urban green transformation method," Journal of Tongji University (Social Sciences), no. 8, p. 37, 2011.

[13] T. L. Saaty, "Fundamentals of Decision Making and Priority Theory with the Analytic Hierarchy Process," RWS Publications, Pittsburg, 1994.

Received: June 10, 2015

Revised: July 29, 2015

Accepted: August 15, 2015

(C) Chongmei Wang; Licensee Bentham Open.

This is an open access article licensed under the terms of the Creative Commons Attribution Non-Commercial License (http://creativecommons.org/licenses/by-nc/3.0/) which permits unrestricted, non-commercial use, distribution and reproduction in any medium, provided the work is properly cited. 